\title{
High frequency ventilation combined with spontaneous breathing during bronchopleural fistula repair: a case report
}

\section{Présentation de cas: addition de ventilation à haute fréquence à la respiration spontanée pendant une réparation de fistule bronchopleurale}

\author{
Véronique Poulin, MD · Rosaire Vaillancourt, MD · \\ Jacques Somma, MD · Nathalie Gagné, PhD • \\ Jean S. Bussières, MD
}

Received: 9 July 2008/Revised: 16 October 2008/Accepted: 28 October 2008/Published online: 20 December 2008

(C) Canadian Anesthesiologists' Society 2008

\begin{abstract}
Purpose We report the addition of high frequency oscillatory ventilation (HFOV), combined with spontaneous breathing under general anesthesia, during an uncommon technique to occlude a late post-pneumonectomy bronchopleural fistula.

Clinical features A 41-year-old woman underwent an extended right pneumonectomy with chest wall resection and prosthetic reconstruction for a large adenocarcinoma of the upper lobe (T3NOMO). Her postoperative recovery was satisfactory, and she subsequently received adjuvant chemotherapy. Four months later, however, she was readmitted for investigation of confusion and pink expectorations. On cerebral magnetic resonance imaging, a frontal metastasis with surrounding edema was discovered, as well as a possible secondary lesion in the occipital lobe. In view of the comorbidities, thoracoscopy was planned as an interim measure, with the goal being to debride the fistula and to seal the prosthetic plug. During this case, a HFOV system was
\end{abstract}

\footnotetext{
V. Poulin, MD

The Department of Anesthesiology, Laval University, Quebec City, Quebec, Canada

R. Vaillancourt, MD

The Thoracic Surgery Service, University Heart and Lung Institute at Laval Hospital, Quebec City, Quebec, Canada

J. Somma, MD · N. Gagné, PhD · J. S. Bussières, MD ( $ه)$ The Department of Anesthesiology, University Heart and Lung Institute at Laval Hospital, 2725 chemin Sainte-Foy, Quebec City, Quebec, Canada G1V 4G5

e-mail: jean.bussieres@anr.ulaval.ca
}

used to allow an addition of $2.5 \mathrm{~L} \cdot \mathrm{min}^{-1}$ of minute ventilation to the patient's spontaneous respiration, while maintaining eucapnia without increasing airway pressure.

Conclusions With the addition of high frequency ventilation under general anesthesia in a patient with a persistent bronchopleural fistula, the $\mathrm{PaCO}_{2}$ level was adequately controlled during the simultaneous use of fibreoptic bronchoscopy and video assisted thoracoscopy to facilitate a successful surgical repair.

\begin{abstract}
Résumé
Objectif Nous rapportons l'ajout du mode de ventilation à haute fréquence par oscillation (VHFO) à la respiration spontanée sous anesthésie générale pendant une technique peu commune visant à réaliser l'occlusion d'une fistule bronchopleurale survenue à la suite d'une pneumonectomie. Éléments Cliniques Une patiente de 41 ans a subi une pneumonectomie droite extensive avec résection de la paroi thoracique et reconstruction prothétique en traitement d'un important adénocarcinome du lobe supérieur (T3NOMO). Sa récupération postopératoire fut satisfaisante et elle reçut par la suite une chimiothérapie adjuvante. Cependant, quatre mois plus tard, elle fut réadmise à l'hôpital pour un examen approfondi de troubles de confusion et d'expectorations rosées. La résonance magnétique cérébrale révéla une métastase frontale entourée d'un odème, ainsi qu'une lésion secondaire potentielle au niveau du lobe occipital. Étant donné les comorbidités, une thoracoscopie a été prévue comme mesure intérimaire, et dont l'objectif était de débrider la fistule et sceller le bouchon prothétique. Pendant cette
\end{abstract}


intervention, un système de VHFO a été utilisé pour permettre l'ajout de 2,5 L.min ${ }^{-1}$ de ventilation minute à la respiration spontanée de la patiente, tout en maintenant l'eucapnie sans augmenter la pression des voies aériennes. Conclusion Grâce à l'ajout d'une technique de ventilation à haute fréquence sous anesthésie générale chez une patiente souffrant d'une fistule bronchopleurale persistante, le niveau de $\mathrm{PaCO}_{2}$ a été contrôlé de façon adéquate pendant l'utilisation simultanée de bronchoscopie par fibre optique et de vidéo-thoracoscopie facilitant la réussite d'une réparation chirurgicale.

Bronchopleural fistula (BPF) is a persistent communication between the tracheobronchial tree and the pleural cavity. Among a variety of reported causes, two-thirds are complications of surgical lung resections. The incidence of BPF occurring after pneumonectomy is about $4-5 \%^{1}$ (more frequently on the right side), and BPF is associated with a high mortality risk. Anesthesiologists have an important role in the management of this pathology. Airflow across the fistula must be minimized while, at the same time, maintaining adequate gas exchange, avoiding tension pneumothorax, and protecting the contralateral lung from crossover contamination. ${ }^{2}$ We report the use of high frequency oscillatory ventilation (HFOV), combined with spontaneous breathing, for the repair of a delayed BPF following pneumonectomy. Written consent for publication was obtained from the patient.

\section{Case description}

A 41-year-old woman underwent an extended right pneumonectomy with chest wall resection and prosthetic reconstruction for a large $\left(12 \times 15 \mathrm{~cm}^{2}\right)$ adenocarcinoma of the upper lobe (T3NOM0). Her postoperative recovery was satisfactory, and she subsequently received adjuvant chemotherapy. Four months later, she was readmitted from an outpatient clinic for investigation of confusion and pink expectorations. On cerebral magnetic resonance imaging, a frontal metastasis with surrounding edema was discovered, as well as a possible secondary lesion in the occipital lobe. Simultaneously, with the right chest cavity showing no pulmonary silhouette on X-ray, a bronchoscopy was done, and a small BPF was diagnosed. Several days later, a thoracoscopy under loco-regional anesthesia was performed at the same time as a bronchoscopy, confirming the presence of a fistula. Thoracoscopic viewing revealed a piece of BioGlue $\AA$ that was originally applied in liquid form at the time of resection and appeared to act as a foreign body with local infection and secondary fistula. The BioGlue ${ }^{\circledR}$ was easily removed; the infected tissue was debrided, and a fibrin glue patch was applied to close the fistula. The immediate result was satisfactory, and the patient was transferred to a neurosurgical team for surgical resection of her brain metastasis and gamma knife treatment of the possible secondary lesion. Unfortunately, following the neurosurgical procedure, a recurrent air leak from the right chest tube was diagnosed, and a new intervention to repair the leak was scheduled for 2 weeks later.

At that time, the patient had stopped receiving dexamethasone following her craniotomy, and she was not optimized to sustain a major procedure, such as a primary surgical closure with muscle flaps. The objective was to "buy" time, to wean the patient from steroids and to treat the chest cavity's Aspergillus infection with ambulatory intravenous antifungal therapy. Since the first attempt lasted 10 days, it was hoped that using a more consistent plug with material known to resist infection, combined with fibrin glue and systemic intravenous antifungal and antibacterial treatment, would offer a chance of cure. ${ }^{3,4}$ The intervention consisted of a combined flexible bronchoscopy with a video-assisted thoracoscopy under general anesthesia. The surgeon's goal was to occlude the fistula by inserting a plug of lyophilized porcine small bowel submucosa (Surgisis ${ }^{\circledR} \mathrm{AFP}^{\mathrm{TM}}$, Cook, Wset Lafayette, IN, USA) into the BPF orifice, with the flexible video-optical bronchoscope (FOB) via the endotracheal tube (ETT) (Fig. 1). A surgical sealant (Tissell ${ }^{\circ}$, Baxter AG, Vienna, Austria) was to secure the plug. Before the intervention, anesthetic planning was discussed to determine the best means to ensure adequate ventilation during the procedure, without interfering with the surgeon who had to perform numerous interventions through the ETT. Controlling the $\mathrm{PaCO}_{2}$ was essential, in view of the coexisting occipital metastasis.

Upon arrival in the operating room, the patient's heart rate was 100 beats. $\min ^{-1}$, arterial blood pressure 120 / $60 \mathrm{mmHg}$, and $\mathrm{SpO}_{2} 100 \%$. The chest drain was functioning. Prior to induction of anesthesia, standard monitors were applied, and an arterial line was inserted. A right paravertebral block was performed with a single injection of $20 \mathrm{ml}$ of bupivacaine $0.5 \%$, plus epinephrine 1:200,000 at the T6 level. The patient was positioned in a semi-sitting position, and the table was tilted to the right so that the fistula was on the dependent side. Anesthesia was induced using sevoflurane in oxygen with spontaneous ventilation and a semi-circle anesthesia breathing circuit. The larynx and the trachea were topically anesthetized with lidocaine $4 \%$, and an $8.5 \mathrm{~mm}$ single lumen ETT (Mallinckrodt, St. Louis, MO, USA) was inserted. The correct position of the tube was confirmed with the FOB. Propofol was infused at $50 \mu \mathrm{g} \cdot \mathrm{kg}^{-1} \cdot \mathrm{h}^{-1}$ in combination with sevoflurane. At the beginning of the procedure, the hemodynamic variables were stable; the respiratory rate was $20 \mathrm{breaths} \cdot \mathrm{min}^{-1}$, and the $\mathrm{SpO}_{2}$ was $100 \%$, while the $\mathrm{EtCO}_{2}$ was $62 \mathrm{mmHg}$. 
Fig. 1 Surgical procedure. $1.1=$ before, $1.2=$ during, $1.3=$ after, $A$ left main bronchus, $B$ main carina, $C$ right main bronchus stump, $D 1$ bronchopleural fistula, $D 2$ insertion of the plug, D3 final occlusion

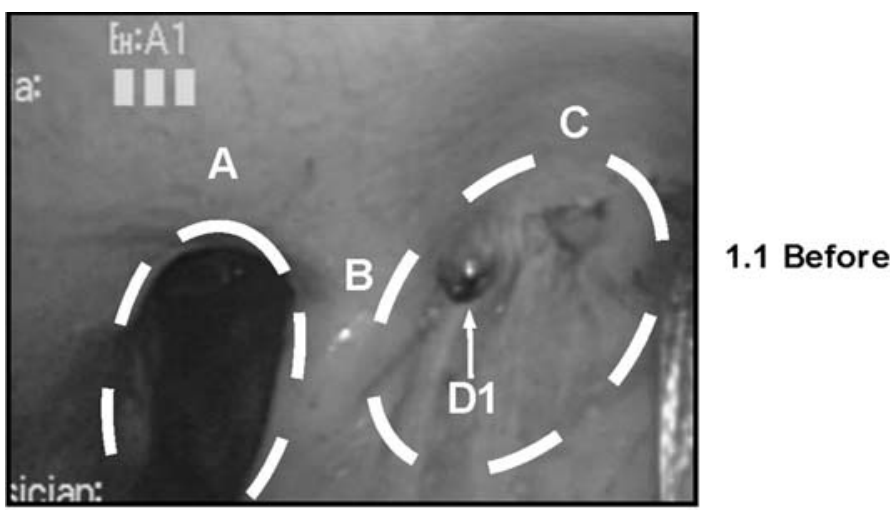

1.2 During
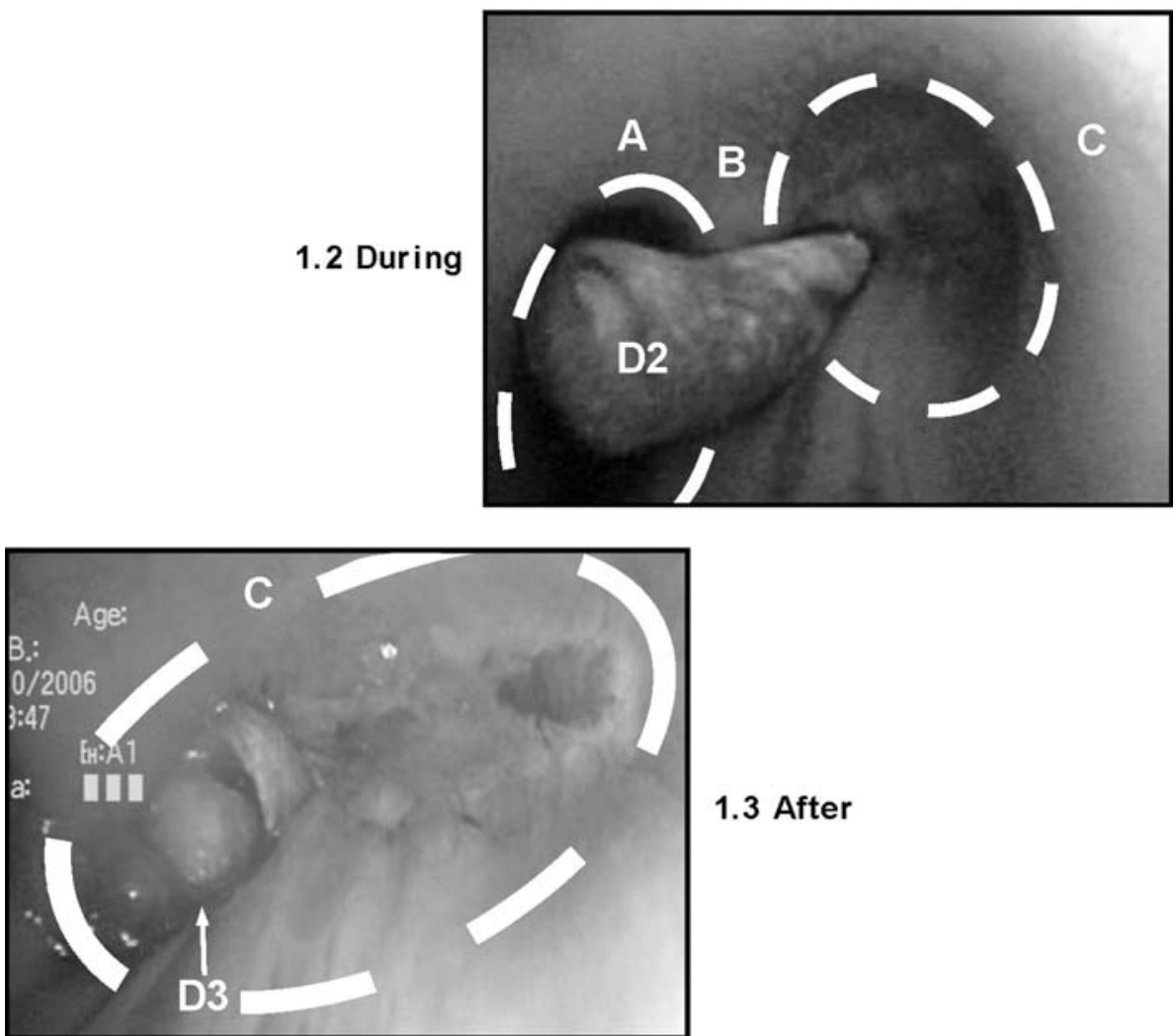

1.3 After
An arterial blood gas confirmed a high $\mathrm{PaCO}_{2}$ of $65.8 \mathrm{mmHg}$ (Table 1, 1.1). At that time, HFOV was started in order to assist spontaneous ventilation. A Siemens Servo HFV 970 ventilator (Siemens Medical Solutions, Erlangen, Germany) was used with the following parameters: continuous mode (inspiration and expiration phase) total minute volume: $2.5 \mathrm{~L} \cdot \mathrm{min}^{-1}$, frequency: $15 \mathrm{~Hz}$, and pulse duration: 50\%. The Servo HFV 970 can provide combined high frequency ventilation in addition to conventional volume or pressure control ventilation. It can be added during inspiratory and/or expiratory phases. The pneumatic oscillator was connected to a $14 \mathrm{G}$ intravenous catheter inserted into the ETT via an Arndt multiport airway adaptor (Fig. 2).

A few minutes after the HFOV was begun, the $\mathrm{ETCO}_{2}$ and $\mathrm{PaCO}_{2}$ decreased significantly (Table 1,1.2). The plug became too soft to be manipulated during the procedure; consequently, it was removed via a rigid bronchoscope. The ETT was replaced by another tube with the same characteristics. The HFOV was then stopped for about $30 \mathrm{~min}$, and the patient was allowed to breathe spontaneously. Elevation of the $\mathrm{ETCO}_{2}$ rapidly ensued (Table 1, 1.3). When the HFOV was resumed, gas exchange improved once again (Table 1, 1.4). Throughout the intervention, the $\mathrm{SpO}_{2}$ remained above $98 \%$, and the respiratory rate remained between 19 and 21 breaths. $\mathrm{min}^{-1}$, with tidal volumes varying between 200 and $250 \mathrm{ml}$. With these settings, gas exchange was adequate for the following 30 min (Table 1, 1.5). The addition of HFOV did not modify the respiratory rate, and the mean airway pressure was $4 \mathrm{~cm} \mathrm{H}_{2} \mathrm{O}$ during the use of HFOV. Finally, the heart 
Table 1 Arterial blood gas values

\begin{tabular}{llllll}
\hline & Timing & Ventilation mode & $\mathrm{pH}$ & $\mathrm{PaCO}_{2}(\mathrm{mmHg})$ & $\mathrm{PaO}(\mathrm{mmHg})$ \\
\hline 1.1 & Post induction & Spontaneous & 7.26 & 65.8 & 459.7 \\
1.2 & First trial & HFVO & 7.42 & 43.2 & 471.1 \\
1.3 & Post re-intubation & Spontaneous & 7.27 & 61.3 & 475.6 \\
1.4 & Second trial & HFVO & 7.37 & 48.1 & 354.9 \\
1.5 & 30 min later & HFVO & 7.37 & 46.8 & 451.4 \\
\hline
\end{tabular}

HFVO high frequency ventilatory oscillation

Fig. 2 Ventilation circuit. A Seimens, Servo HFV 970 and the pneumatic unit, $B$ ventilatory circuit, $B 1$ anesthesia breathing circuit, $B 2$ Arndt multiport adaptor, $B 3$ minibore extension set arising from the pneumatic unit, $C$ intravenous catheter $14 \mathrm{G}$ that was introduced in the lateral side port of the Arndt multiport adaptor and squeezed to keep it tightly in place

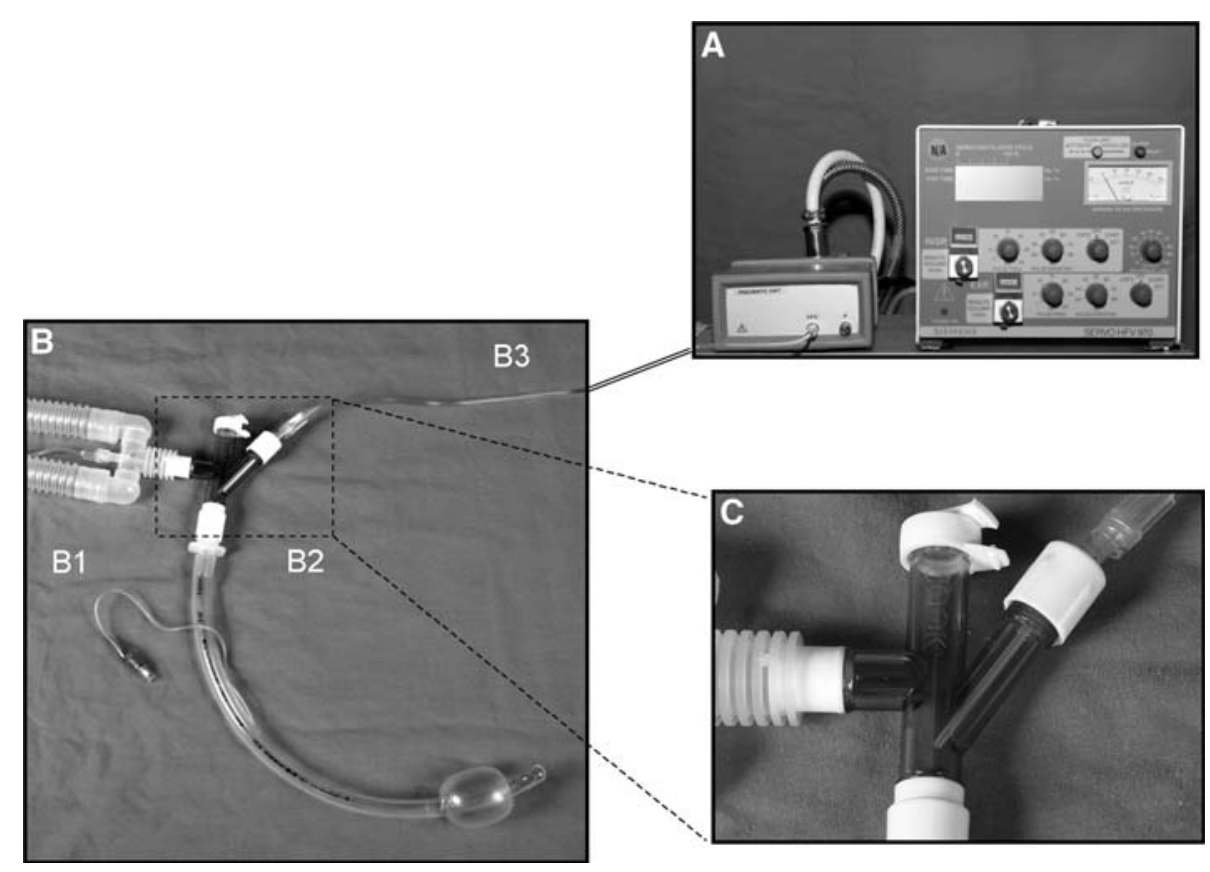

rate and the arterial pressure also remained stable (100-120/min and 100-120/40-60 mmHg, respectively).

The remaining intervention was uncomplicated; the HFOV was discontinued, and emergence from anesthesia was uneventful. The patient's trachea was extubated a few minutes after the end of the procedure. The plug remained perfectly tight for about a week. A small low flow leak reappeared, but was well tolerated by the patient. She was discharged from the hospital with a chest drain still in place. During this period, she remained at home with her family, and she was gradually weaned from steroids while under antibiotic therapy. After 6 weeks, she was readmitted for definitive closure of her BPF with intercostal muscle flap and thoracoplasty. She has since recovered from her surgery with no residual sign of recurrent BPF.

\section{Discussion}

We report the successful use of HFOV, combined with spontaneous ventilation, during an uncommon technique to occlude a late post-pneumonectomy BPF in a patient who recently had a cerebral metastasis treated by radiotherapy and surgery.

Proper management of patients with BPF requires understanding that the air leak through a BPF is dependent on the pressure gradient between the mean airway pressure at the site of the fistula and the interpleural space. The fact that the chest was not wide open with a thoracic window, but drained with a $24 \mathrm{Fr}$ chest tube, provided enough resistance to minimize this gradient and allow the patient to be eupneic at room air.

In the literature, many options are described to provide artificial ventilation for these patients. ${ }^{2}$ Classically, the most convenient way to manage patients is to rapidly establish lung isolation by intubating the unaffected bronchus, either with a double-lumen tube or with a long single lumen tube. The planned procedure required the largest tracheal tube available, and, therefore, we chose to install a single-lumen tube at the tracheal level.

Spontaneous ventilation has also been described as a way to ventilate patients with a BPF during induction as 
well as throughout maintenance of anesthesia. ${ }^{2}$ Advantages include decreasing the risk of tension pneumothorax and optimizing the matching of ventilation and perfusion. On the other hand, the possibility of aspiration during induction and the risk of contamination of the healthy lung constitute possible drawbacks of this technique. In this case, we considered it was the best way to provide surgical access to the fistula, while minimizing the air leak. Maintenance of a reliable anesthetic depth using spontaneous ventilation is challenging. Manual assistance of the spontaneously breathing patient was not attempted. The BPF was sufficiently large that the use of positive pressure ventilation would have resulted in an unacceptable flow leak through the BPF. Paravertebral blocks were performed to optimize the anesthetic, and the trachea was anesthetized with topical lidocaine (thus avoiding narcotics). Propofol was infused in combination with sevoflurane to minimize the respective side effects of higher concentrations of either drug used alone.

High frequency ventilation has been advocated as an alternative technique to achieve adequate or improved gas exchanges at lower peak and mean airway pressures in patients with BPF. ${ }^{2}$ In a recent case report, HFOV has been described as a useful technique to manage a high output BPF when conventional positive pressure ventilation failed. ${ }^{5}$ However, older studies did not show better outcomes in terms of gas exchange, airway pressures, or air leak. ${ }^{6,7}$

Few articles describe the combination of high frequency ventilation with spontaneous breathing. ${ }^{8}$ One case report described the use of spontaneous ventilation combined with high frequency jet ventilation during bronchoscopic resection of a large tracheal tumour in a patient who had a learning disability. This technique allowed safe management of the airway, treatment of desaturation, and assisted ventilation while performing the surgery efficiently. ${ }^{9}$ However, in a recently published bench study, spontaneous breathing during HFOV resulted in more difficult breathing, especially for adults. ${ }^{10}$ Until the development of efficient demand-flow systems, ${ }^{11}$ this ventilation technique must be reserved for short duration interventions under close monitoring.

The type of HFOV system used during this case allowed an addition of $2.5 \mathrm{~L} \cdot \mathrm{min}^{-1}$ of minute ventilation to the patient's spontaneous ventilation, which represents a 20 $33 \%$ increase in total minute ventilation without having significantly increased airway pressure. In a patient with an intracerebral mass lesion, any further increase in intracranial pressure caused by inhaled anesthetics and hypercarbia might have led to cerebral ischemia and neuronal damage. ${ }^{12}$ This is why, when the $\mathrm{PaCO}_{2}$ reached $60 \mathrm{mmHg}$, we decided to incorporate an alternative mode of ventilation in addition to spontaneous breathing. Moreover, it has been shown in anesthetized dogs that HFOV, at both low and high airway pressures, is safe in relation to cerebral blood flow and oxygen delivery. ${ }^{13}$

This case report shows the successful use of HFOV, in addition to spontaneous ventilation under general anesthesia. This technique was used in a patient with a cerebral metastasis recently treated by radiotherapy and surgery, who presented for closure of a BPF. The combination of HFOV and spontaneous breathing adequately controlled the $\mathrm{PaCO}_{2}$ level and provided adequate conditions to successfully perform a simultaneous fiberoptic bronchoscopic and video-assisted thoracoscopy procedure.

Conflicts of interest None declared.

\section{References}

1. Kozian A, Schilling T, Strang $C$, Hachenberg T. Anesthetic considerations in patients with previous thoracic surgery. Curr Opin Anaesthesiol 2006; 19: 26-33.

2. Kaplan JA, Slinger PD. Thoracic Anesthesia. 3rd ed. Philadelphia: Elsevier; 2003.

3. Lois $M$, Noppen $M$. Bronchopleural fistulas: an overview of the problem with special focus on endoscopic management. Chest 2005; 128: 3955-65.

4. West D, Togo A, Kirk AJ. Are bronchoscopic approaches to postpneumonectomy bronchopleural fistula an effective alternative to repeat thoracotomy? Interact Cardiovasc Thorac Surg 2007; 6: 547-50.

5. Ha DV, Johnson $D$. High frequency oscillatory ventilation in the management of a high output bronchopleural fistula: a case report. Can J Anesth 2004; 51: 78-83.

6. Spinale FG, Linker RW, Crawford FA, Reines HD. Conventional versus high frequency jet ventilation with a bronchopleural fistula. J Surg Res 1989; 46: 147-51.

7. Bishop MJ, Benson MS, Sato P, Pierson DJ. Comparison of highfrequency jet ventilation with conventional mechanical ventilation for bronchopleural fistula. Anesth Analg 1987; 66: 833-8.

8. Rimensberger PC. Allowing for spontaneous breathing during high-frequency oscillation: the key for final success? Crit Care 2006; 10: 155 .

9. Satoh M, Hirabayashi $Y$, Seo N. Spontaneous breathing combined with high frequency ventilation during bronchoscopic resection of a large tracheal tumour. Br J Anaesth 2002; 89: 641-3.

10. van Heerde $M$, van Genderingen HR, Leenhoven $T$, Roubik $K$, Plotz FB, Markhorst DG. Imposed work of breathing during high-frequency oscillatory ventilation: a bench study. Crit Care 2006; 10: R23.

11. van Heerde M, Roubik $K$, Kopelent V, Plotz FB, Markhorst DG. Unloading work of breathing during high-frequency oscillatory ventilation: a bench study. Crit Care 2006; 10: R103.

12. Gutstein $H B$, Koblin $D D$. Craniotomy for tumor in a patient with a bronchopleural fistula: anesthetic considerations. Anesthesiology 1987; 67: 804-6.

13. Gioia FR, Harris AP, Traystman RJ, Rogers MC. Organ blood flow during high-frequency ventilation at low and high airway pressure in dogs. Anesthesiology 1986; 65: 50-5. 